\title{
Avaliação da aprendizagem em filosofia: uma experiência estética
}

\author{
Evaluation of learning in philosophy: an aesthetic experience
}

\author{
Patrício Câmara Araújo \\ Professor doutor do Instituto Federal do Maranhão, São Luís, MA, Brasil. \\ patriciofilosofia@gmail.com - http://orcid.org/0000-0002-4252-1475
}

Recebido em 27 de setembro de 2020

Aprovado em 27 de setembro de 2021

Publicado em 08 de novembro de 2021

RESUMO: Avaliar a aprendizagem de estudantes de ensino médio em uma componente curricular possibilita indicadores para a construção de estratégias de ensino nessa disciplina. Nesse sentido, este estudo é uma abordagem multimétodo, a partir de uma pesquisa avaliação sobre uma experiência de aprendizagem de estudantes que participaram de um projeto de extensão. O objetivo deste estudo foi avaliar o processo de aprendizagem da análise e produção filosófica de textos no contexto de realização de um projeto de extensão com estudantes de ensino médio. Participou do projeto um grupo de estudantes do segundo ano do ensino médio, que a partir de oficinas sobre análise filosófica de narrativas mitológicas gregas, mediadas por discussão coletiva, elaboraram textos redacionais que relacionavam a narrativa lida com algum problema sociocultural ou histórico. A partir do conhecimento produzido foi construída uma apresentação teatral, enquanto experiência estética, direcionada a alunos do ensino médio de uma escola pública estadual, para estimular a leitura e a interpretação de textos clássicos. Após a realização do projeto, foi aplicado um questionário on-line para avaliar a experiência dos estudantes, participantes do projeto, quanto à aprendizagem sobre a compreensão de conceitos, perspectivas de análise e produção filosófica de textos. O resultado da pesquisa indica que os estudantes participantes do projeto desenvolveram habilidades de interpretação e produção de textos em uma perspectiva filosófica.

Palavras-chave: Avaliação; Aprendizagem; Filosofia; Estética.

ABSTRACT: Evaluating the learning of high school students in a curricular component provides indicators for the construction of teaching strategies in this discipline. In this sense, this study is a multi-method approach, based on an evaluation research on a learning experience of students who participated in an extension project. The aim of this study was to evaluate the learning process of analysis and philosophical production of texts in the context of carrying out an extension project with high school students. Participated in the project a group of students of the second year of high school, at the time of the project, who from workshops on philosophical analysis of Greek mythological narratives, mediated by collective discussion, prepared the editorial texts that related the narrative deals with some sociocultural problem or history. Then, based on the knowledge produced, was built a theatrical presentation, as an aesthetic experience, aimed at high school students from a state public school, to encourage reading and interpretation of classic texts. After completing the project, an online questionnaire was applied to assess the experience of students, participants of the project, regarding learning about the understanding of 
concepts, perspectives of analysis and philosophical production of texts. The result of the research indicates that the students participating in the project developed skills in interpreting and producing texts in a philosophical perspective.

Keywords: Evaluation; Learning; Philosophy; Aesthetics.

\section{Introdução}

O ensino de filosofia exige dos estudantes o desenvolvimento dos processos de abstração, argumentação, organização lógica do pensamento, elaboração de texto e exposição retórica. Criar espaços alternativos à sala de aula para, através de interações dialógicas, promover um ensino voltado à construção de um pensamento criativo, autônomo, crítico e reflexivo é contribuir para a formação de um estudante que consiga problematizar o seu contexto social, a partir de um uso rigoroso de conceitos filosóficos. Isso sem se limitar a períodos históricos da filosofia ou mesmo à abordagem de sistemas filosóficos, mas, também, possibilitando ao estudante o contato com excertos de textos filosóficos rigorosamente selecionados de acordo com o nível de compreensão dos estudantes.

O projeto de extensão "Narrativas Mitológicas: na fronteira entre o mundo antigo e o contemporâneo" foi desenvolvido em 2012, com aprovação por edital, e, também em 2019, com aprovação por edital. O objetivo do projeto foi promover a leitura e interpretação de narrativas mitológicas, a partir de uma análise filosófica que buscasse a contextualização com problemas socioculturais e históricos da atualidade. Esse projeto de extensão possibilitou informações referentes à experiência dos estudantes em 2019.2, que foram analisadas nesta pesquisa.

Sobre a literatura clássica destacamos os mitos gregos por serem constitutivos de um conjunto conceitual e de uma articulação discursiva eivada de figuras de linguagem. Além de apresentarem narrativas que podem ser problematizadas e analisadas para compreendermos o cenário histórico-cultural e sócio-político em que vivemos. Visto que a atualização das narrativas mitológicas pode ser verificada no mundo contemporâneo através das linguagens do cinema, das artes plásticas, nos jogos de internet, nos jogos de videogame e nas imagens propagandísticas, portanto, no cotidiano dos estudantes 
do ensino médio, que foi o público-alvo desta pesquisa. Até mesmo um filme se torna um texto de acordo com a temática a ser estudada (ALVES; SILVA, 2017).

A questão da leitura de narrativas mitológicas se apresenta na utilização dos mitos como caminho de compreensão de diferentes significados sociais e reside em uma pergunta ainda mais radical, a saber: qual a atitude inicial do filosofar? Esse problema foi visitado por Bornheim (2009) ao considerar a admiração (do grego thauma) como promotora de um alcance reflexivo e aberto ao horizonte de sentido, que se mostra ao humano. Um caminho promovido pelo contato com a leitura das narrativas mitológicas.

Essa admiração mantém uma conexão intuitiva com a natureza. Assim, a experiência do mito é a experiência do concreto, pois mostra a realidade sensível em seu contexto sócio-histórico. No mito, há o indivíduo possuidor de uma consciência teorética por compreender o homem como mais um dentre os entes do cosmos, e a natureza concebida para além de algo a ser dominado, como alvo da ciência moderna.

Buzzi (2007) considera que com a tecnologia contemporânea, a natureza não mais passou a ser concebida como aliada do homem, antes se mostrou vitimada pelo desejo de poder e domínio da tecnologia; pois, no contexto moderno do mundo tecnológico, há uma distância entre o homem e a natureza. Logo, o mito como unificador identitário das culturas e promotor de um saber tradicional legítimo, que unia o homem como a totalidade da natureza e da vida, perdeu a sua força. O encanto da tecnologia submeteu o homem à maquinária cartesiana orgânica. O mundo passou, então, a ser escrito em caracteres matemáticos para relembrar Galileu.

Dessa forma, o lugar do mito - como também da lenda - enquanto narrativas na construção textual e na herança de uma tradição ocidental, é significativo. Ressaltamos a diferença entre o mito e a lenda. O objetivo do mito é a origem, e a lenda tem o propósito de instruir, por isso das lendas serem úteis nos processos didáticometodológicos, através do uso de paradidáticos. Isso faz das narrativas um elemento relevante para promover a experiência filosófica, e, portanto, conceitual. Além de promover, através do contato com essas narrativas, o desenvolvimento da habilidade de leitura e interpretação textual dos estudantes, também a capacidade de problematizar seu contexto sociocultural e histórico. 
O caráter alegórico dessas narrativas possibilitou o uso pelos filósofos, mesmo em um contexto diferente da mitologia. Platão usou essa linguagem alegórica em seu mito da caverna:

[...] "Alegoria" não é uma palavra utilizada por ele, mas ela expressa adequadamente o que ele pretendeu fazer. Ela significa algo como "dizer de outro modo", isto é, afirmar alguma coisa que poderia ser dita de outro modo. [...] Nessa alegoria, o interior da caverna simboliza o mundo sensível, mundo ilusório e enganador, que é como sombras se comparado com a realidade das formas ou ideias. O exterior da caverna representa então essa realidade. (FIGUEIREDO, 2006, p. 46-47).

Assim, a alegoria, enquanto figura de linguagem das narrativas mitológicas, aparece como um recurso textual rico de possibilidades comparativas. Platão apresenta como a filosofia já se apropriava de uma textualidade alegórica, presentes nos textos míticos, para promover uma experiência do conceito. Experiência que o contato com essas narrativas, orientada por uma discussão filosófica sobre elas, pode ser promovida.

Uma narrativa mitológica se constitui enquanto um meio textual que possibilita o desenvolvimento de habilidades necessárias para uma reflexão filosófica (ALVES; SILVA, 2017). Os mitos gregos possibilitam a problematização de conceitos como razão, verdade, aparência, justiça, para citar alguns, em perspectiva filosófica.

\section{Ensino de Filosofia e Narrativas Mitológicas}

A leitura de uma narrativa mítica por um viés filosófico possibilita um diálogo com a apresentação de uma concepção de mundo em que um conjunto de enunciados é articulado em um todo semântico. Nesse todo, estão presentes significados que circularam no mundo grego e podem ser relacionados aos conceitos estudados em filosofia no ensino médio, além dos já citados, temos como exemplo: conhecimento, ética, política, ciência, lógica e estética.

A problematização de conceitos não é o único alvo da aprendizagem no ensino de filosofia. Os alunos também precisam se apropriar dos signos que circulam nos textos filosóficos, mas, sobretudo, da lógica de análise desse tipo de texto. O uso do texto filosófico no ensino de filosofia é relevante, pois: 
[...] não somente se trata de compreender o autor e sua elaboração, mas de apreender e se apropriar da lógica específica da reflexão filosófica, das regras, particularidades e dificuldades de seu exercício por meio da leitura, comentários e discussões do texto (ALVES; SILVA, 2017).

O ensino da componente curricular filosofia promove a aprendizagem de conhecimentos como: a construção de um pensamento argumentativo, compreensão do uso da linguagem, capacidade de abstrair e elaboração de uma oralidade e um processo de escrita coerente (RODRIGO, 2015). Diante disso, o desafio é possibilitar um ensino de filosofia que lide com as dificuldades de um ensino médio que apresenta problemas didático-metodológicos e sociais, além de desafiar professores a construírem estratégias de ensino criativas, que construam pontes de diálogo entre os conteúdos filosóficos, e promovam o desenvolvimento dos processos de análise, leitura e produção textual em diálogo com o contexto sociocultural e histórico do estudante. Os conteúdos na filosofia implicam no próprio filosofar, o que inclui as suas questões, linguagens e conceitos (ASPIS, 2004).

Ensinar uma componente curricular é apresentar um conjunto de signos relacionado a elas, como: palavras, conceitos, expressões e imagens. Conhecer esses signos e usá-los dentro do contexto semântico do texto filosófico é aprender quando esses signos possibilitam uma experiência do pensamento e não uma assimilação de representações anunciadas pelo professor (PINTO et al, 2015). Por isso, a filosofia, ao problematizar conceitos e explorar aspectos semânticos de uma palavra, atribuindo-lhe plasticidade - uso o termo no sentido de uma flexibilidade semântica, diante da interpretação dos estudantes- está promovendo a emancipação do pensamento do indivíduo.

A emancipação do pensamento é promovida pela experiência filosófica. Não se trata de explicar ao aluno que não tem conhecimento, mas de promover uma compreensão da realidade que, na concepção deleuzeana está para além de uma fixação de preconceitos que se transformam em sentenças, as quais se constituem em um enquanto (PINTO et al, 2015), representações que desconsideram a complexidade da significação. 
O estudo desenvolvido por Pinto et al (2015) teve como objetivo apresentar quais os resultados foram obtidos em um projeto de extensão, que buscou promover a experiência filosófica em um espaço não formal, com adolescentes em conflito com a lei em um regime de semiliberdade de uma instituição socioeducativa. A experiência possibilitou explorarem o ensino de filosofia para além das fronteiras do ensino formal.

Rodrigo (2015) defende que há a necessidade da construção de um saber pedagógico que converta a tradição filosófica em algo que possa ser ensinado ao público do ensino médio. Uma das formas de se fazer isso é traduzir os conhecimentos da filosofia em um contexto estético, através do uso de linguagens das artes, que podem ser a música, a pintura e/ou o teatro. A linguagem teatral possibilita uma organização lógica das cenas a serem apresentadas pelos alunos, o que pode funcionar em analogia com a sequência lógica de produção textual. Produzir redações implica em desenvolvimento de uma organização lógica do pensamento e da elaboração de justificativas a partir de um processo argumentativo (Rodrigo, 2015).

Tornar a filosofia acessível ao público do ensino médio é um desafio que começa com o professor. Ele deve, como ressaltou Rodrigo (2015, p. 53), "[...] ser autor do seu discurso didático", que significa elaborar um jeito próprio de comunicar o ensino. Contexto em que deve possibilitar ao estudante condições de desenvolver a aprendizagem de habilidades necessárias para a reflexão crítica sobre a realidade.

No processo de ensino da filosofia, o professor deve utilizar mediadores didáticometodológicos para tornar os conceitos, problemas e perspectivas da filosofia acessíveis aos estudantes. Uma das formas de alcançar esse objetivo é construir espaços de conversação e de produção textual sobre textos selecionados em diálogo com o contexto dos estudantes e de acordo com o nível de compreensão de cada um, diagnosticado previamente. Tais espaços podem estar relacionados a projetos de ensino, pesquisa ou extensão que estimulem os estudantes ao protagonismo de uma atitude filosófica diante de seu contexto social.

Esses mediadores podem ser utilizados na Zona de Desenvolvimento Proximal (ZDP). Esse é um conceito elaborado por Vigotski, em sua perspectiva histórico-cultural, e se refere àquilo que o estudante ainda não sabe fazer sozinho, somente com um mediador. A ZDP é a distância entre o desenvolvimento real, no qual resolve problemas 
sem a orientação de alguém, e de desenvolvimento potencial, em que resolve problemas por alguém (MOREIRA, 2018). Nesse contexto, o professor precisa promover o ensino que oriente o estudante a uma aprendizagem autônoma, de um desenvolvimento real.

Entendo que nesse processo, em que o professor utiliza mediadores didáticos para conduzir os estudantes à aprendizagem, ele pode usar textos filosóficos, desde que tenha orientado previamente os estudantes para uma análise filosófica. Uma oportunidade para isso é usar as narrativas mitológicas. Platão fez isso com o seu tão conhecido "mito da caverna" e que tem sido utilizado para discussões filosóficas no ensino médio, por ser uma alegoria que traz elementos complexos de forma acessível, em certa medida, para uma iniciação à filosofia.

As narrativas mitológicas gregas são eivadas de imagens e possibilidades de relações, sobretudo no contexto da filosofia, ao permitir uma maior aproximação com o mundo grego. Rodrigo (2015) comenta:

[...] Assim, a imaginação, por meio de metáforas, exemplos, analogias, comparações, etc., pode atuar como apoio para se chegar ao pensamento conceitual. A intertextualidade ou diálogo entre textos de diferentes gêneros e registros - orais, escritos, visuais, música, literatura, cinema, etc. também podem ser um recurso interessante para alcançar esse objetivo.

Entre os registros da citação anterior, incluo o teatro, por possibilitar um contexto para o protagonismo de estudantes, que atuam como atores em um enredo que eles mesmos podem construir. É uma experiência estética que dialoga com a filosofia. A experiência estética tem caráter dialógico e é diferente de outras experiências no contexto cultural (MARKOVIĆ, 2012; PERNIOLA, 1998), pois ela é construída em um espaço-tempo, que vincula os processos psicológicos às experiências de cada indivíduo em uma situação concreta (KEUNEN, 2015).

O professor que participa desse processo tem uma experiência filosófica ao usar mediadores semióticos, como os significados, textos e recursos didático-metodológicos como a dramatização teatral - e os elementos artísticos envolvidos na construção do cenário, do figurino e da sonoplastia, para citar alguns. Aspis (2004) destaca que a experiência filosófica de ensinar envolve a constituição do aluno por ele e por seu professor. Também afirma que a aula de filosofia é uma produção filosófica. Nesse 
sentido, reconhecemos que um projeto escolar também pode se constituir enquanto uma produção de filosofia, quando promove o desenvolvimento de habilidades de abstração, a organização lógica do pensamento, a produção de textos, através de um processo argumentativo, e a exposição retórica com clareza.

Com a orientação necessária, o estudante poderá se posicionar de forma crítica diante dos temas, conceitos, períodos históricos da filosofia e sistemas filosóficos. Ressalto a célebre afirmação kantiana na Crítica da Razão Pura, de que não se ensina a filosofia, mas a filosofar. Perspectiva que está relacionada à autonomia da razão, do indivíduo que assume um posicionamento próprio diante das diversas concepções filosóficas. Diferente do kantismo, o idealismo hegeliano compreende que apreender os conteúdos filosóficos já é em si mesmo estar filosofando. Assim, não há diferença entre filosofia e filosofar, são momentos interdependentes, pois [...] filosofia é filosofar e filosofar é filosofia (ASPIS, 2004, p.308).

Os conceitos filosóficos, assim como os sistemas e os temas, são dinâmicos e complexos. O conteúdo da filosofia está em constante reelaboração para dialogar com a época em que os conceitos são ensinados, e o professor de filosofia precisa de um posicionamento dialógico, que responde aos enunciados do seu aluno em uma interlocução na qual é responsável pelo que ensina. Uma educação, enquanto resposta responsável contra discriminações, estereótipos, exclusões, para a construção de diferentes formas de ver e compreender. É um processo de interação dialógica em que os sentidos são produzidos e os significados são compartilhados por consciências socialmente organizadas (VOLÓCHINOV, 2017).

A sala de aula, assim como outros espaços escolares de realização das interlocuções entre professor e alunos, possibilita um contexto de problematização de conceitos filosóficos. Esse é um processo reativo em que o professor ensina e aprende com os alunos, em um encontro que promove um olhar multiperspectívico sobre a realidade.

\section{Metodologia}

Esta foi uma pesquisa avaliação sobre o processo da experiência de aprendizagem de filosofia em um projeto de extensão com estudantes de ensino médio. 
Consideramos que eles desenvolveram uma experiência filosófica através da participação nesse projeto. A pesquisa avaliação pode ser considerada enquanto um processo de descrição sistemática sobre um processo ou produto com o objetivo de apresentar o seu valor (MOREIRA; CALEFFE, 2008).

Diante disso, perguntamos: em que medida é possível o desenvolvimento de uma aprendizagem significativa dos conhecimentos em filosofia, a partir de um projeto de extensão que realize uma análise filosófica sobre narrativas mitológicas gregas? Essa é uma questão relacionada ao ensino de filosofia em um espaço não formal de ensino. Moreira (2018) comenta que na perspectiva rogeriana, a aprendizagem se torna significativa para o estudante quando ele percebe que ela é importante para seu engrandecimento pessoal e lhe possibilita alcançar seus objetivos.

O projeto de extensão foi desenvolvido por uma equipe com 12 participantes, (4) quatro professores e (8) oito estudantes do segundo ano do ensino médio integrado ao técnico, todos de uma instituição pública de ensino. Os estudantes eram de dois cursos: (1) um do curso técnico em agenciamento de viagem e os outros (7) sete do curso técnico em agroecologia, (4) quatro mulheres e (4) quatro homens, com a idade entre 16 e 19 anos à época da pesquisa.

Os estudantes foram convidados para participarem do projeto de extensão e se reuniam uma vez por semana com o coordenador do projeto. Eles leram o texto mitológico selecionado, através da relação com algum problema atual e que provocasse a curiosidade.

O projeto de extensão apresentou como principal meta a realização de uma exposição artística, com a realização de contação da narrativa mitológica, seguida de sua dramatização com o uso de slides. Diante disso, foi realizada uma exposição cênica da peça teatral "As Asas de Ícaro". Trata-se de uma narrativa mitológica que discute os limites da técnica e sua concepção tanto no mundo antigo como no mundo contemporâneo. O evento aconteceu após a seleção da narrativa, construção de textos redacionais sobre ela pelos alunos do projeto, e da construção do enredo, figurino, falas e cenário por parte dos alunos. Isso com a orientação dos professores, servidores voluntários do projeto, e do coordenador. 
A encenação teatral aconteceu em uma escola estadual de ensino médio. A escola cedeu o espaço para a realização da encenação teatral, cortina, tela de napa para a projeção dos slides durante a peça, caixa de som e microfone. Durante o evento, participaram em torno de 120 estudantes de ensino médio de (7) sete turmas: (3) três do primeiro ano, (2) dois do segundo ano e (2) do terceiro ano, conforme informou o diretor. Eles assistiram à encenação teatral elaborada pelos estudantes de ensino médio de uma instituição pública de ensino. O projeto de extensão apresentou (6) seis resultados:

1) Promoção da interação dialógica entre os estudantes e os servidores voluntários do projeto, através do whatsapp, de forma a possibilitar a dinâmica das reuniões e atividades. Além da circulação de informações, sobre o projeto, no grupo dos voluntários, professores e estudantes.

2) Aproximação entre instituições públicas de ensino através do diálogo com o gestor de outra instituição pública de ensino, no que se refere à disponibilidade, dessa instituição, em aceitar o projeto. Além de apresentar a relevância, a esse gestor, do projeto sobre narrativas mitológicas, para a promoção do estímulo e estratégias de leitura e interpretação de texto clássico aos estudantes.

3) Deliberação, junto aos estudantes voluntários, do protagonismo na interpretação/contextualização das narrativas mitológicas e nos ensaios da dramatização, peça teatral, sobre o mito selecionado, "As Asas de Ícaro". Os ensaios aconteceram com improvisações planejadas. Reverbel (2009) define a improvisação planejada como uma técnica aplicada em uma expressão dramática, na qual os estudantes criam uma cena a partir de uma situação e, depois, constroem um roteiro da cena, para ser apresentada.

4) Desenvolvimento de outros produtos/processos relacionados às diferentes linguagens artísticas, que podem ser utilizadas para a exposição criativa da narrativa mitológica grega, tais como: objetos cênicos e seleção de sonoplastia clássica grega e contemporânea relacionada a ela.

5) Desenvolvimento de conceitos filosóficos, com a leitura e discussão das narrativas mitológicas e com a elaboração de textos dissertativos de caráter críticoreflexivo sobre os mitos; além da parte prática, necessária para a elaboração da exposição criativa da peça teatral, com seus figurinos, cenário e ensaios. 
6) Maior aproximação entre comunidades estudantis da instituição pública que desenvolveu o projeto e da escola pública estadual que o recepcionou.

Para a construção dessa experiência no projeto de extensão, que envolveu o ensino de filosofia com estudantes do ensino médio, foram desenvolvidas (4) quatro atividades. Essas se referem à seleção do campo de desenvolvimento da ação de extensão, organização dos encontros do projeto de extensão, a realização das discussões, com a análise filosófica de narrativa mitológica, com orientações sobre produção textual, até à construção e encenação da peça teatral elaborada pelos estudantes.

$1^{a}$ Atividade: Seleção de uma escola pública do entorno da instituição pública de ensino. Para esta seleção foram considerados os critérios de: a) proximidade geográfica com a instituição de ensino; b) ter turmas de ensino médio; c) ter turmas com disponibilidade de participação dos encontros do projeto, dentro dos horários que não gere incômodo aos alunos da escola; e d) a aceitação da direção da escola, mediante solicitação por ofício, encaminhado pelo orientador do projeto.

$2^{a}$ Atividade: Agendamento dos dias em que foram realizados os encontros de leitura com os alunos do ensino médio da instituição pública de ensino. A seleção dos alunos aconteceu mediante entrevista com o orientador do projeto. Os critérios da seleção foram: a) apresentar disponibilidade para reuniões semanais em horários a combinar com o orientador e coorientadores; e b) demonstrar interesse e habilidade para a interpretação de narrativas da mitologia grega.

$3^{a}$ Atividade: Realização dos encontros a partir da escolha dos mitos a serem lidos e discutidos, em perspectiva filosófica, em grupo. Após a discussão os alunos elaboraram textos dissertativos, em perspectiva filosófica.

4 $^{a}$ Atividade: Construção de apresentação teatral, com performance escolhida pelos alunos, para os discentes na escola pública selecionada.

Para essas atividades foram utilizados como materiais um notebook, Datashow, caixa de som, materiais de papelaria e impresso, além de celulares para realização das fotografias. A avaliação dos alunos, quanto à participação no projeto, foi atitudinal e contínua. Nela, consideramos a frequência nas reuniões, o envolvimento nos debates 
sobre as narrativas, o processo de construção dos textos dissertativos e a participação na construção e realização das apresentações.

Utilizamos a análise temática sobre as narrativas mitológicas selecionadas. A análise temática é um método analítico de pesquisa qualitativa de caráter dinâmico, com a identificação de temas retomados e relacionados (SILVA; BORGES, 2017). O Contexto de realização dessa análise foi o das reuniões realizadas com os estudantes em (2) duas etapas: 1) a identificação de conceitos e temas, que emergiram da leitura sobre as narrativas mitológicas, através de um diálogo crítico-reflexivo; e 2) a elaboração de questões contextualizadas, com temáticas socioculturais, sobre as narrativas mitológicas.

\section{Resultados e Discussão}

Cada participante apresentou três relatórios mensais. Sobre os relatórios destacamos: 1) as atividades desenvolvidas e 2) as dificuldades para a realização delas, que estão relacionadas conforme a tabela 1 abaixo 
Tabela 1 - Atividades e dificuldades no desenvolvimento do projeto de extensão

\begin{tabular}{|c|c|c|}
\hline MÊS & ATIVIDADES & DIFICULDADES \\
\hline \multirow{4}{*}{ Set/Out } & $\begin{array}{l}\text { 1. Leitura analítica da narrativa } \\
\text { mitológica "As Asas de İ́caro"; }\end{array}$ & $\begin{array}{l}\text { 1.1 Promover uma contextualização da } \\
\text { narrativa com problemas socioculturais } \\
\text { e históricos contemporâneos; }\end{array}$ \\
\hline & $\begin{array}{l}\text { 2. Análise e discussão do texto com } \\
\text { os alunos; }\end{array}$ & 2.1 Construção do texto dissertativo; \\
\hline & $\begin{array}{l}\text { 3. Problematização das palavras da } \\
\text { narrativa }\end{array}$ & $\begin{array}{l}\text { 3.1 Caracterizar as personagens da } \\
\text { narrativa; }\end{array}$ \\
\hline & $\begin{array}{l}\text { 4. Construção de texto dissertativo } \\
\text { que relacionou a narrativa mitológica } \\
\text { com um problema contemporâneo. }\end{array}$ & $\begin{array}{l}\text { 4.1 Visualização e construção das } \\
\text { cenas. }\end{array}$ \\
\hline \multirow{4}{*}{ Out/Nov } & $\begin{array}{l}\text { 5. Construção da peça teatral - } \\
\text { caracterização das personagens; }\end{array}$ & $\begin{array}{l}5.1 \text { Identificar as músicas mais } \\
\text { adequadas para a peça teatral, de } \\
\text { acordo com a cultura grega; }\end{array}$ \\
\hline & $\begin{array}{l}\text { 6. Seleção das músicas para a } \\
\text { sonoplastia; }\end{array}$ & $\begin{array}{c}\text { 6.1 Construir os elementos cênicos para } \\
\text { a peça teatral; }\end{array}$ \\
\hline & $\begin{array}{l}\text { 7. Elaboração os elementos cênicos } \\
\text { e do cenário da peça; }\end{array}$ & \multirow{2}{*}{$\begin{array}{l}\text { 7.1 Ensaiar as cenas: perfil das } \\
\text { personagens; }\end{array}$} \\
\hline & $\begin{array}{l}\text { 8. Ensaios com os alunos } \\
\text { voluntários. }\end{array}$ & \\
\hline \multirow{4}{*}{ Nov/Dez } & $\begin{array}{l}\text { 9. Ensaiar as cenas: perfil das } \\
\text { personagens; }\end{array}$ & $\begin{array}{l}\text { 8.1 Promover uma contextualização das } \\
\text { personagens da narrativa com os } \\
\text { problemas socioculturais e históricos } \\
\text { contemporâneos; }\end{array}$ \\
\hline & $\begin{array}{l}\text { 10. Ensaiar as cenas: perfil das } \\
\text { personagens; }\end{array}$ & $\begin{array}{l}\text { 9.1 Construção de texto dissertativo a } \\
\text { partir da discussão das ações das } \\
\text { personagens; }\end{array}$ \\
\hline & 11. Construção do figurino; & $\begin{array}{l}\text { 10.1 Construção de texto dissertativo, } \\
\text { que considerasse aspectos culturais; }\end{array}$ \\
\hline & 12. Revisão da sonoplastia. & $\begin{array}{l}\text { 11.1 Seleção das músicas relacionadas } \\
\text { ao contexto grego e que ao mesmo } \\
\text { tempo estivesse de acordo com o } \\
\text { significado da discussão filosófica. }\end{array}$ \\
\hline
\end{tabular}

Fonte: Autor.

Após a realização do projeto de extensão encaminhamos um questionário para os estudantes participantes, com questões sobre a experiência deles no projeto de extensão; dos (8) oito participantes, (7) sete responderam. O link do questionário on-line foi enviado aos estudantes no grupo de whatsapp do projeto de extensão, com a preservação do anonimato dos participantes quanto às respostas. O questionário tinha (5) questões direcionadas para avaliar a experiência de participar de um projeto de extensão e do desenvolvimento da aprendizagem em filosofia construída pelos estudantes através da ação extensionária. A elaboração das questões seguiu o critério de serem específicas sobre: 1) a relação entre a aprendizagem dos conhecimentos de 
filosofia e sobre 2) o desenvolvimento das habilidades de análise e produção textual. Em seguida, apresentamos os gráficos das perguntas do questionário on-line com o título: "Projeto de extensão: narrativas mitológicas".

Figura 1 - Pergunta sobre participação em projeto de extensão

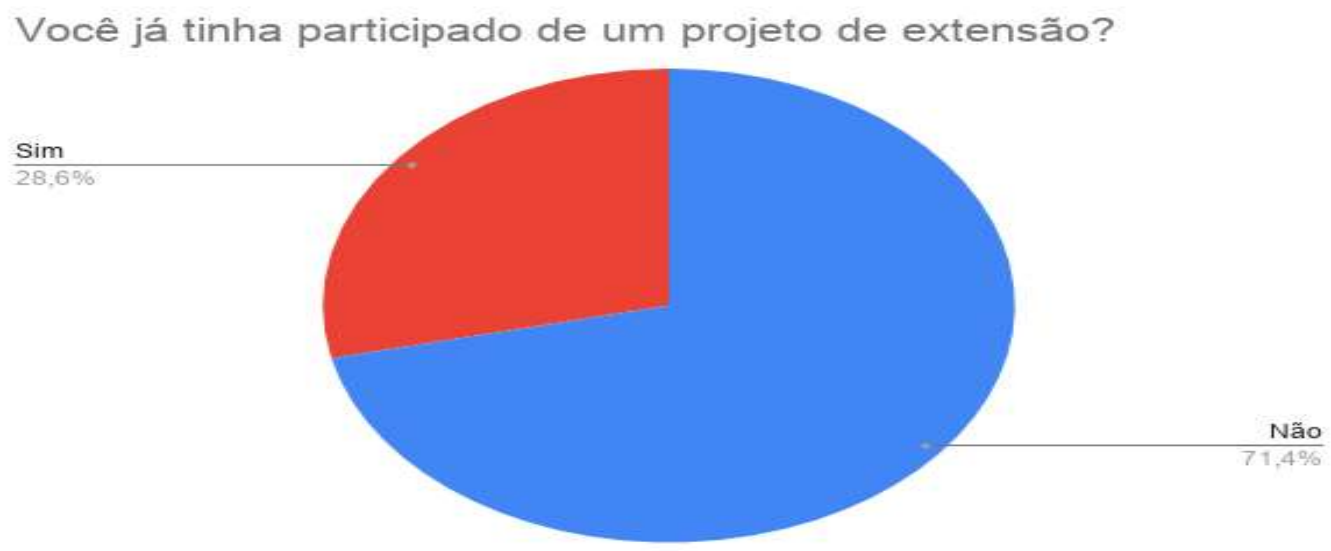

Fonte: Autor.

A pergunta (1): você já tinha participado de um projeto de extensão? É relevante na medida em que permite identificar o caráter inaugural dessa experiência para o estudante (ver Figura 1). Ter participado de um projeto de extensão pode contribuir para uma melhor compreensão sobre a aprendizagem de conteúdos disciplinares em espaços não formais.

Com a pergunta (2) dois: como você avaliaria a sua experiência no projeto de extensão? Buscamos identificar como o próprio estudante avaliou a sua experiência em um projeto de extensão. Entre as opções: muito relevante, pouco relevante e irrelevante, sobre as quais $85,7 \%$ consideraram que a experiência foi muito relevante e $14,3 \%$ que foi pouco relevante (ver Figura 2).

A avaliação do próprio participante se constitui enquanto uma valorização do posicionamento que ele assumiu acerca de sua experiência na ação extensionária. A relevância indica aprendizado com desenvolvimento de habilidades em filosofia (ver Figura 3). A que respondeu que a participação foi pouco relevante, consideramos que pode ter sido pelo pouco envolvimento nas atividades do projeto, o interesse em outros saberes que não são filosóficos ou uma fragilidade na forma e/ou na proposta de 
realização do projeto, como também na ausência de um acompanhamento docente mais próximo dos participantes durante as atividades.

Figura 2 - Pergunta sobre a experiência dos estudantes no projeto de extensão

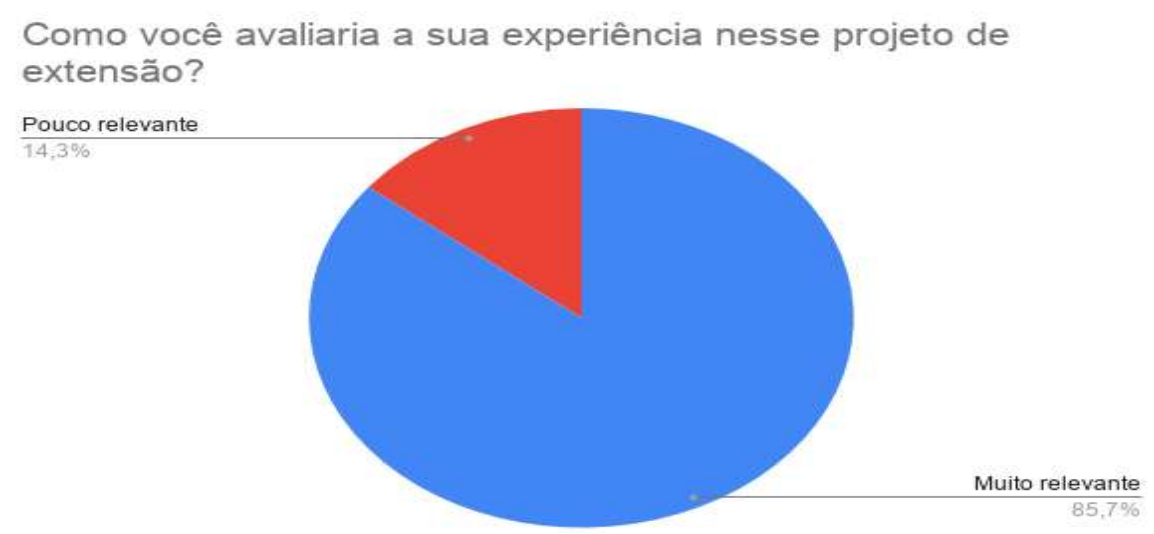

Fonte: Autor.

Em seguida, com a pergunta (3) três: a experiência no projeto de extensão contribuiu para seus conhecimentos em Filosofia? O objetivo foi avaliar como os estudantes relacionaram essa experiência aos conhecimentos em filosofia.

Figura 3 - Pergunta sobre a aprendizagem da filosofia

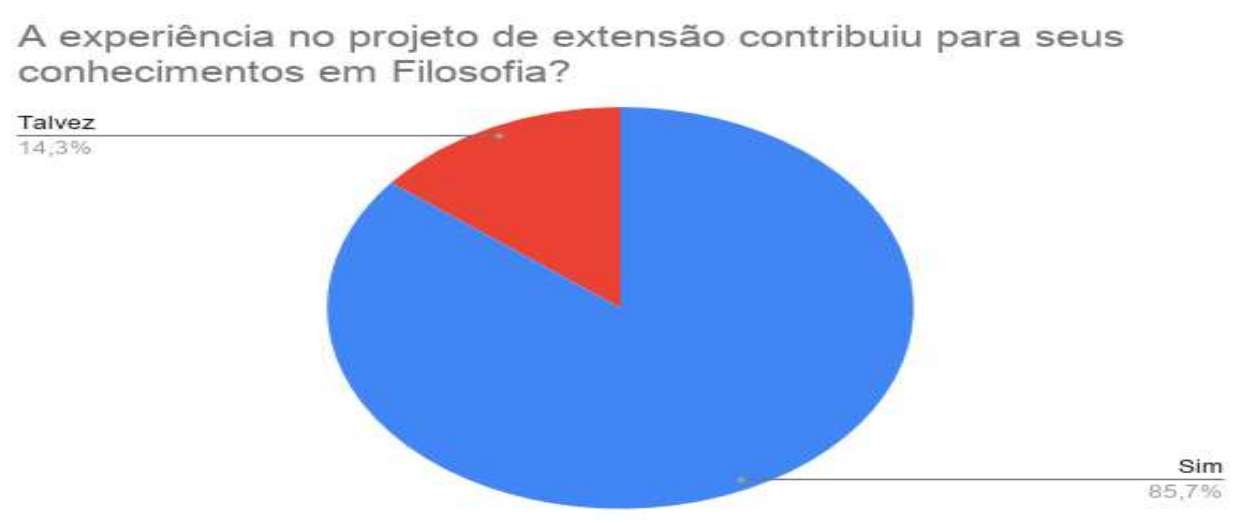

Fonte: Autor.

A percepção dos participantes de que as atividades do projeto estavam diretamente relacionadas a conhecimento em filosofia indica que eles entenderam o foco 
de ensino dessa experiência. A pergunta (4) quatro: a experiência no projeto de extensão contribuiu para melhorar a sua análise e produção textual?

Figura 4 - Pergunta sobre o desenvolvimento da produção textual

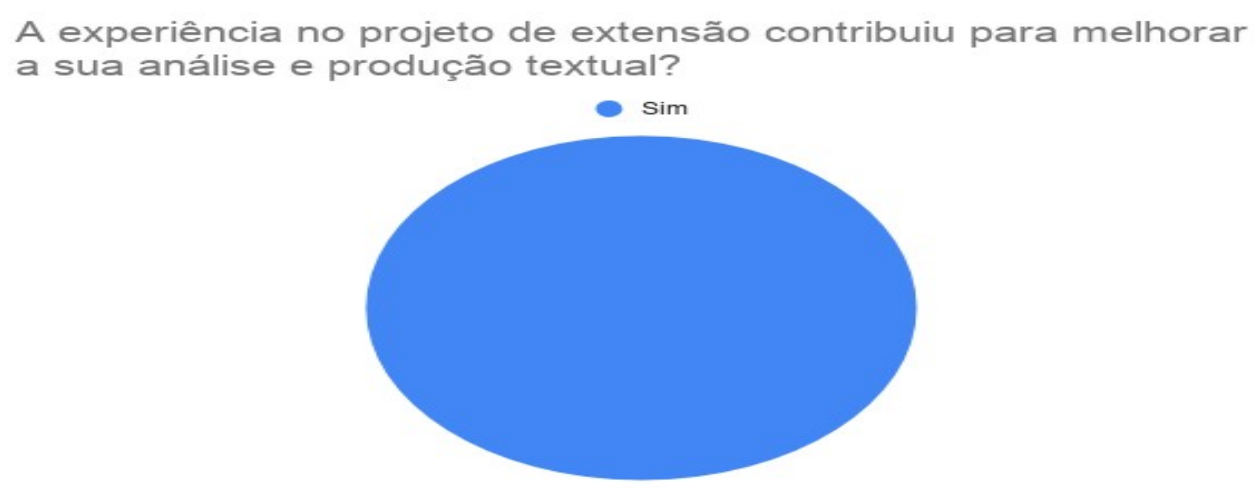

Fonte: Autor.

$\mathrm{Na}$ Figura 4 o objetivo foi avaliar o desenvolvimento da habilidade de análise e produção textual. Sobre isso todos afirmaram que o projeto trouxe essa contribuição. Diferente da Figura 3, na qual a aprendizagem do conhecimento de filosofia foi da maioria. Contudo, a melhoria na interpretação e escrita de textos é uma habilidade necessária para a experiência filosófica. Dessa forma, esses conhecimentos e habilidades se relacionam no contexto do projeto.

Ainda para a avaliação de como o estudante considerou essa experiência em uma ação extensionária para a sua aprendizagem, de produção textual e dos conhecimentos em filosofia, elaboramos a pergunta (5) cinco: você indicaria para outros estudantes a experiência de participar de um projeto de extensão desse tipo? Todos afirmaram que indicariam essa experiência (ver Figura 5). Essas respostas indicam a contribuição do projeto para a formação educacional dos estudantes. 
Figura 5 - Pergunta sobre a indicação do projeto de extensão

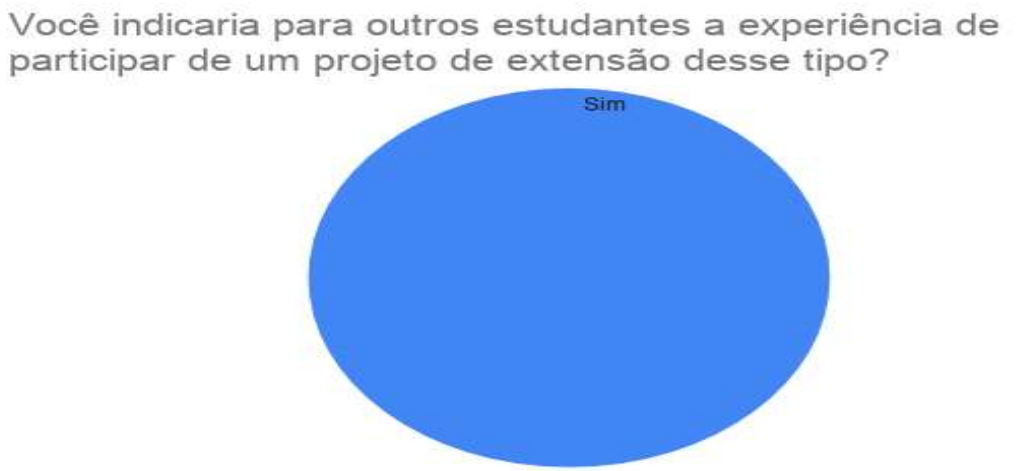

Fonte: Autor.

A experiência - possibilitada pelo projeto de extensão - de caráter estético estava diretamente relacionada ao processo de leitura, análise, discussão e elaboração de texto filosófico. O processo dedutivo de organização de um texto narrativo, orientado pelo coordenador do projeto aos estudantes participantes, possibilitou um delineamento lógico das produções redacionais dos alunos (ver Figura 4).

A leitura crítico-reflexiva dos estudantes sobre a narrativa "As asas de Ícaro" orientou a construção do enredo da peça, por mesmo nome, em uma lógica narrativa que dialogava com o contexto do problema do otimismo sobre a tecnologia. Isso porque a diegese, enquanto processo narrativo do mito, apresenta Ícaro e o seu pai Dédalo presos na ilha de Creta, pelo rei Minos, por terem entregado o fio de Ariádine a Perseu, que o usou para fugir do labirinto. Dédalo inventou asas para ele e para o seu filho fugirem da ilha, durante o voo Ícaro caiu e morreu.

A discussão com os estudantes foi sobre em que medida podemos confiar na técnica. Discutimos que os instrumentos tecnológicos produzidos pelos humanos precisam ser usados com responsabilidade. Assim, com perguntas e inferências o processo conversacional foi se desdobrando. Nesse contexto, quando os textos foram discutidos, perguntamos sobre as palavras que os estudantes relacionavam à discussão filosófica da narrativa mitológica. Para Bakhtin (2015), palavras são signos ideológicos, por estarem relacionadas a sentidos e valores. As palavras que os estudantes apresentaram indicam os posicionamentos que assumiram diante do seu próprio 
contexto sociocultural (ver Tabela 1, atividade 3). Destacamos as palavras que circularam no mundo grego relacionando-as ao mundo contemporâneo.

\begin{abstract}
A palavra, primitivamente, é mito. Interior ao mito e condição sua, o "logos" humano vai conquistando primazia, com a inteligência das mãos que transformam o mundo. Os primórdios dessa história ainda é mitologia: o mito é objetivado pela palavra que o diz. A narração do mito, no entanto, objetivando o mundo mítico e entrevendo o seu conteúdo racional, acaba por devolver à consciência a autonomia da palavra, distinta das coisas que ela significa e transforma. Nessa ambigüidade com que a consciência faz o seu mundo, afastando-o de si, no distanciamento objetivante que o presentifica como mundo consciente, a palavra adquire a autonomia que a torna disponível para ser recriada na expressão escrita (FREIRE, 1987, p. 11).
\end{abstract}

Nesse sentido, os estudantes, a partir de orientações de produção textual, construíram redações que foram corrigidas pelo coordenador. Inseriram tópicos frasais, reescreveram expressões subjetivas e relacionaram os parágrafos para produzir coesão e coerência. Isso através do uso de palavras com significados que evidenciavam o pensamento grego, e, a partir deles, os participantes problematizavam o seu próprio mundo. A perspectiva filosófica estava em questionar de forma crítica o uso da técnica e das tecnologias e relacionar a atitude de Ícaro a um posicionamento 'ingênuo' diante das possibilidades de uso dos produtos industrializados, como celulares, carros e alimentos transgênicos; por isso a importância de construir o perfil das personagens (ver Tabela 1, atividade 9).

O processo de tradução dessa análise filosófica para a linguagem do teatro apresentou a mesma dificuldade inicial, tanto na produção dos textos redacionais como na construção das cenas, enquanto um conjunto de ações sobre uma temática (REVERBEL, 2009). A dificuldade foi a de estabelecer relações lógico-dedutivas, com o desenvolvimento da argumentação no processo de produção textual.

\title{
Considerações finais
}

O objetivo dessa pesquisa foi avaliar o processo de aprendizagem da análise e produção filosófica de textos no contexto de realização de um projeto de extensão com estudantes de ensino médio. Avaliamos que os estudantes desenvolveram, em certa 
medida, as competências/habilidades para a leitura, interpretação e produção de texto filosófico. As informações indicaram que as experiências de aprendizagem dos estudantes na disciplina de filosofia foram construídas através da participação no projeto de extensão "Narrativas Mitológicas: na fronteira entre o mundo antigo e o contemporâneo", enquanto estratégia de ensino de filosofia em um contexto educacional fora da sala de aula.

Realizar uma pesquisa avaliação sobre um projeto de extensão, em contexto educacional é, sobretudo, destacar a contribuição dessa experiência para a aprendizagem dos participantes. Avaliação que não pode deixar de considerar a percepção dos participantes quanto a essa ação extensionária; motivo que orientou as perguntas do questionário.

Outras pesquisas de avaliação podem ser realizadas acerca dos projetos de extensão no ensino médio. Os objetos de investigação podem ser: a aprendizagem, a percepção, a constituição dos sujeitos, a prática discursiva, bem como outros elementos do contexto educacional. Assim, a aprendizagem dos estudantes e a forma de avaliar uma ação extensionária mostram a relevância dessa pesquisa.

\section{Referências}

ALVES, Antônio José Lopes; SILVA, Sabina Maura Ensinar filosofia para ensinar a filosofar. Acta Scientiarum. Human and Social Sciences, Maringá, v. 32, n. 2, p. 177186, maio/ago. 2017.

ASPIS, Renata Pereira Lima. O professor de filosofia: o ensino de filosofia no ensino médio como experiência filosófica. Caderno CEDES, Campinas, v. 24, n. 64, p.305-320, set./dez. 2004.

BAKHTIN, Mikhail Mikhailovich Estética da criação verbal. Tradução de Paulo Bezerra. São Paulo: WMF Martins Fontes, 2015.

BORNHEIM, Gerd Alberto. Introdução ao filosofar: o pensamento filosófico em bases existenciais. São Paulo: Globo, 2009.

BULFINCH, Thomas. O livro de ouro da mitologia: Histórias de deuses e heróis. 34 ed. Rio de Janeiro: Ediouro, 2006. 
BUZZI, Arcângelo R. Introdução ao Pensar: o ser, o conhecimento, a linguagem. 33a ed. Petrópolis, RJ: Vozes, 2007.

FIGUEIREDO, de Vinícius (org.). Seis filósofos na sala de aula. São Paulo: Berlendis \& Vertecchia, 2006.

FREIRE, Paulo. Pedagogia do oprimido. Rio de Janeiro: Paz e Terra, 1987.

KEUNEN, Bart. A Imaginação Cronotópica na Literature e no Cinema: Bakhtin, Bergson, Deleuze em formas de tempo. In BEMONG, Nele et al. Bakhtin e o cronotopo:

Reflexões, aplicações, perspectivas. São Paulo: Parábola Editorial, 2015. p. 52-77.

MARKOVIĆ, Slobodan. Components of aesthetic experience: Aesthetic fascination, aesthetical appraisal, and aesthetic emotion. I-Perception, v. 3, n. 1, p. 1-7.

DOI:10.1068/i0450aap, 2012.

MOREIRA, Marco Antonio. Teorias da Aprendizagem. São Paulo: E.P.U, 2018.

MOREIRA; Herivelton; CALEFFE, Luiz Gonzaga. Metodologia da pesquisa para o professor pesquisador. Rio de Janeiro: Lamparina, 2008.

PERNIOLA, Mario. A Estética do Século XX. Lisboa: Editorial Estampa, 1998.

PINTO, Silmara Cristiane et al. Ensino de Filosofia em espaços não formais: notas de uma experiência. Educação/Santa Maria, v. 40, n. 31, p.657-670, set./dez. 2015. DOI: http://dx.doi.org/10.5902/1984644415857

REVERBEL, Olga Garcia. Jogos Teatrais na Escola. São Paulo: Scipione, 2009.

RODRIGO, Lídia Maria. Filosofia no ensino médio: metodologias e práticas de ensino.

Cadernos do Núcleo de estudos sobre Ensino de Filosofia, v. 1, n. 1, p.51-58, 2015.

SILVA, Cátia Cândido da; BORGES, Fabrícia Teixeira. Análise temática dialógica como método de análise de dados verbais em pesquisas qualitativas. Linhas Críticas, Brasília, DF, v. 23, n. 51, p.245-267, jun./set. 2017.

VOLÓCHINOV, Valentin. Marxismo e filosofia da linguagem. Tradução de Sheila Grilo e Ekaterina Vólkova Américo. São Paulo: Editora

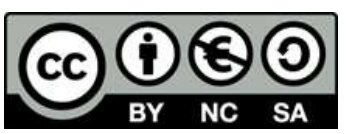

This work is licensed under a Creative Commons Attribution-NonCommercial 4.0 International (CC BY-NC 4.0) 